\title{
Easy Way to Electronic Converter Designers to Design a Buck Converter Application for Photovoltaic Systems
}

\author{
Samir Mouhadjer \\ URMER Research unit, \\ Tlemcen University, Algeria
}

\author{
Ali Chermitti \\ URMER Research unit, \\ Tlemcen University, Algeria
}

\author{
Amar Neçaibia \\ URER-MS Research Unit in \\ renewable energies. Adrar, \\ Algeria
}

\begin{abstract}
More sophisticated applications require electronic converters to process the electricity from the PV device. These converters may be used to regulate the voltage and current at the load, control the power flow in grid-connected systems, and mainly track the maximum power point (MPP) of the device. Therefore, this paper tries to study an electronic converter in PV systems, namely the Buck converter, and propose an easy way to electronic converter designers to calculate component values needed to realize it.
\end{abstract}

\section{General Terms}

Photovoltaic power generator, Optimization system, Power, Regulation, inverter efficiency.

\section{Keywords}

Photovoltaic generator, Optimization, Power, Regulation, efficiency.

\section{INTRODUCTION}

The reason to choose a Buck converter is that our load is a $12 \mathrm{v}$ lead-acid battery, where we will charge it with only one $\mathrm{PV}$ module which generates the most watts running at around $17 \mathrm{v}$. Thus, we need a DC/DC converter which takes a higher input voltage and converts it to a lower output voltage. This can only be done by the Buck converter. We will, first, start by a brief introduction to the functioning of a Buck converter, and then, write its basic equations [10, 12].

\section{HOW DOES A BUCK CONVERTER WORK}

\subsection{Circuit description:}

The basic circuit of a Buck converter is shown below in Figure 1.

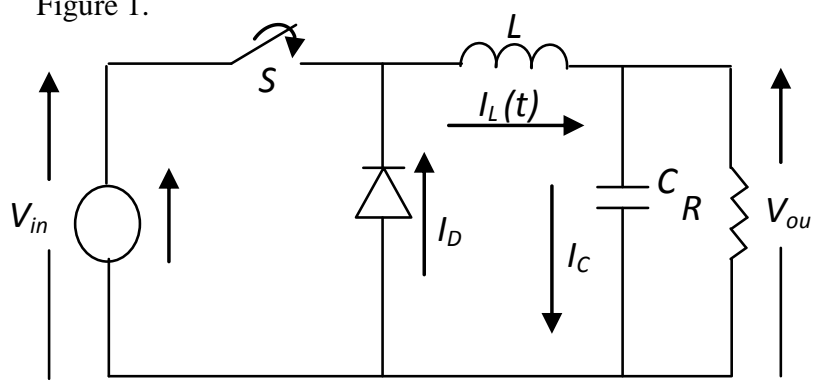

Fig. 1 Basic circuit of a Buck converter
Two switches are used in this basic circuit, usually one controlled (MOSFET) and one uncontrolled (diode), to achieve unidirectional power flow from the input to the output. This circuit, also, uses one capacitor and one inductor to store and transfer energy from input to output. They, also, filter or smooth voltage and current [8].

\subsection{Circuit operation:}

We used inductors and capacitors as energy storage components to control the energy flow from the input to the output by continuously opening and closing the switch which is usually an electronic device that operates in two states:

When the switch is ON for a time duration $\alpha \mathrm{T}$ ( $\alpha$ is the duty cycle), the switch conducts the inductor current and the diode becomes reverse biased. This results in a positive voltage $\mathrm{V}_{\mathrm{L}}=\mathrm{V}_{\mathrm{in}}-\mathrm{V}_{\mathrm{ou}}$ across the inductor.

This voltage causes a linear increase in the inductor current $\mathrm{I}_{\mathrm{L}}$. When the switch is turnedOFF, because of the inductive energy storage $I_{L}$ continues to flow.

This current now flows through the diode, and $V_{L}=-V_{o u}$ for time duration $(1-\alpha) T$ until the switch is turned $O N$ again. [1]

\subsection{Analytical expressions:}

The basic circuit of the Buck converter showed in Figure 1 has two energy storage elements: the inductor and capacitor which can be calculated in a second order differential equation.

We start by the differential equation for the capacitor voltage, in the ON state, which given by:

$$
L C \frac{d^{2} V_{c}}{d t^{2}}+\frac{L}{R} \frac{d V_{c}}{d t}+V_{c}(t)=V_{i n}
$$

Assumption: $V_{c}(t)$ is constant, so the differential equation above can be simplified and can be written for the current through the inductor as:

$$
L \frac{d I_{L}(t)}{d t}=V_{i n}-V_{o u}
$$

For a steady stat, and when $t \rightarrow T_{O N}=\alpha T$ the inductor current attains it final value:

$$
I_{L}=\frac{V_{i n}-V_{o u}}{L} \alpha T+I_{L 0}
$$


Where $\mathrm{I}_{\mathrm{L} 0}$ is the initial value of the inductor current (just before the switch is turned on). The peak-to-peak current ripple $\Delta \mathrm{I}_{\mathrm{L}}$ is the difference between the final and initial value of $\mathrm{I}_{\mathrm{L}}$ and is given by:

$$
\Delta I_{L}=I_{L}-I_{L 0}=\frac{V_{\text {in }}-V_{o u}}{L} \alpha T
$$

This proportionality between the current ripple and the duty cycle prove that $\Delta \mathrm{I}_{\mathrm{L}}$ can be controlled by $\alpha$.

For OFF state, we have a first order differential equation (the inductor current flows through the diode):

$$
\mathrm{L} \frac{\mathrm{d}_{\mathrm{L}}(\mathrm{t})}{\mathrm{dt}}=-\mathrm{V}_{\text {ou }}
$$

The solution of the differential equation yields:

$$
I_{L}(t)=\frac{-V_{\text {ou }}}{\mathrm{L}} \mathrm{t}+\mathrm{I}_{\mathrm{L}}
$$

Now, for $\mathrm{t} \rightarrow \mathrm{T}_{\mathrm{OFF}}=(1-\alpha) \mathrm{T}$ the inductor current decreases to its minimum value $\mathrm{I}_{\mathrm{L} 0}$ therefore: $\mathrm{I}_{\mathrm{L} 0}=\frac{-\mathrm{V}_{\mathrm{ou}}}{\mathrm{L}}(1-\alpha) \mathrm{T}+\mathrm{I}_{\mathrm{L}}$

So, we can obtain the equation of the current ripple:

$$
\Delta \mathrm{I}_{\mathrm{L}}=\mathrm{I}_{\mathrm{L}}-\mathrm{I}_{\mathrm{L} 0}=\frac{\mathrm{V}_{\text {ou }}}{\mathrm{L}}(1-\alpha) \mathrm{T}
$$
that:

By a simple comparison between (4) and (8) it is obvious

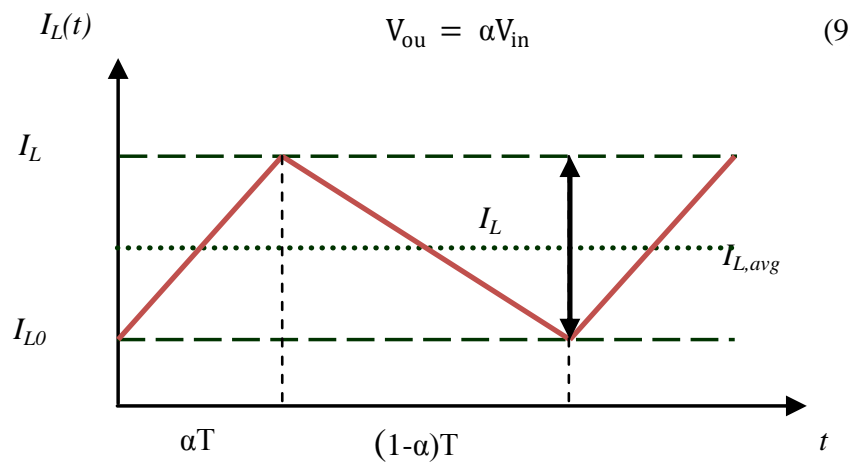

Fig. 2 inductor current waveform

To obtain the average inductor current, we can use:

$$
\mathrm{I}_{\mathrm{L}, \mathrm{avg}}=\frac{\mathrm{V}_{\text {ou }}}{\mathrm{R}}
$$

Therefore, the maximum and the minimum current through the inductor are:

$$
\begin{gathered}
\mathrm{I}_{\mathrm{L}, \text { max }}=\mathrm{I}_{\mathrm{L}, \text { avg }}+\frac{\Delta \mathrm{I}_{\mathrm{L}}}{2} \\
=\frac{\mathrm{V}_{\text {ou }}}{\mathrm{R}}+\frac{\mathrm{V}_{\text {ou }}}{2 \mathrm{~L}}(1-\alpha) \mathrm{T} \\
\mathrm{I}_{\mathrm{L}, \text { min }}=\mathrm{I}_{\mathrm{L}, \text { avg }}-\frac{\Delta \mathrm{I}_{\mathrm{L}}}{2}=\frac{\mathrm{V}_{\text {ou }}}{\mathrm{R}}-\frac{\mathrm{V}_{\text {ou }}}{2 \mathrm{~L}}(1-\alpha) \mathrm{T}
\end{gathered}
$$

We can now with the same analysis obtain the maximum and minimum current trough the capacitor:

$$
\begin{aligned}
& \mathrm{I}_{c, \text { min }}=\frac{\Delta \mathrm{I}_{\mathrm{L}}}{2}=\frac{\mathrm{V}_{\text {ou }}}{2 \mathrm{~L}}(1-\alpha) \mathrm{T} \\
& \mathrm{I}_{\mathrm{c}, \text { min }}=-\frac{\Delta \mathrm{I}_{\mathrm{L}}}{2}=-\frac{\mathrm{V}_{\text {ou }}}{2 \mathrm{~L}}(1-\alpha) \mathrm{T}
\end{aligned}
$$

The waveform for the current through the capacitor is shown below:

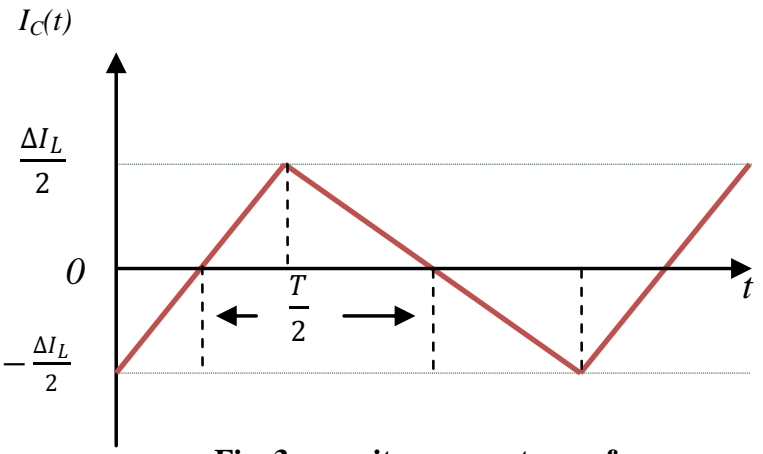

Fig. 3 capacitor current waveform

From Figure3, it's clearly that the average current through the capacitor is zero, but in one-half cycle the capacitor will charged and the increase in charge is:

$$
\Delta \mathrm{Q}=\frac{1}{2} \frac{\Delta \mathrm{I}_{\mathrm{L}}}{2} \frac{\mathrm{T}}{2}=\frac{1}{8} \Delta \mathrm{I}_{\mathrm{L}} \mathrm{T}
$$

and because $V_{c}=V_{\text {ou }}$, the increase in capacitor voltage is:

$$
\Delta \mathrm{V}_{\mathrm{ou}}=\frac{\Delta \mathrm{Q}}{\mathrm{C}}
$$

Then from (8) and (15) we obtain:

$$
\Delta \mathrm{V}_{\mathrm{ou}}=\frac{1}{8 \mathrm{LCf}^{2}} \mathrm{~V}_{\mathrm{ou}}
$$

In continuous conduction mode (CCM);

$\mathrm{I}_{\mathrm{L}, \text { min }}=0$ (the minimum current can be zero at the time of switching), so from (12) we have:

$$
\frac{\mathrm{V}_{\text {ou }}}{\mathrm{R}}=\frac{\mathrm{V}_{\text {ou }}}{2 \mathrm{~L}}(1-\alpha) \mathrm{T}
$$

Then if the desired switching frequency $f$ and load resistance $\mathrm{R}$ are established, the minimum inductor current required for $\mathrm{CCM}$ is:

$$
\mathrm{L}_{\min }=\frac{\mathrm{R}}{2 \mathrm{f}}(1-\alpha)
$$

Likewise we can obtain:

$$
\begin{aligned}
\mathrm{f}_{\min } & =\frac{\mathrm{R}}{2 \mathrm{~L}} \\
\mathrm{R}_{\min } & =\frac{2 \mathrm{fL}}{(1-\alpha)}
\end{aligned}
$$

\section{BUCK CONVERTER DESIGN EXAMPLE}

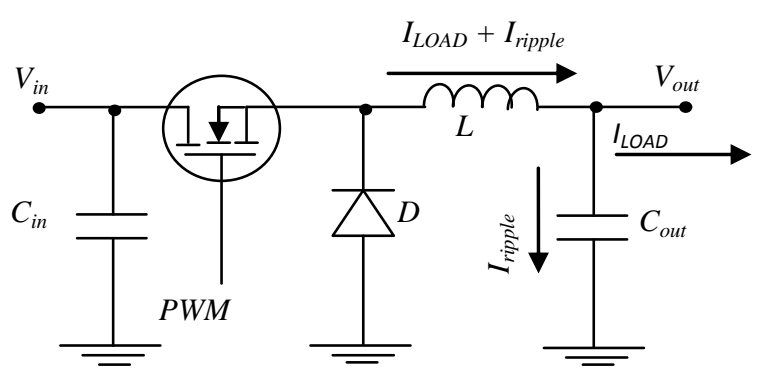

Fig.4 Buck converter design example

Figure 4 shows the design of the Buck converter for which we will present an easy method to select component values: either a P-channel or an N-channel MOSFET may be used. In order 
to determine input capacitor, diode, MOSFET characteristics, one first needs to calculate the required inductor and output capacitor specifications. We will then, with the selected components, calculate the system's efficiency.

\subsection{Inductor selection:}

In our application we need to convert a $17 \mathrm{v}$ power source to an output of $12 \mathrm{v}$ to charge a lead-acid battery by using only one PV module (PHOTOWATT PWX500) where we fixed the output current around 2Amps for more efficiency [9].

Table I

PWX 500 PV module characteristics

\begin{tabular}{|l|l|}
\hline Typical power & $45 \mathrm{~W}$ \\
\hline Minimal power & $40.1 \mathrm{~W}$ \\
\hline Typical power voltage & $17 \mathrm{~V}$ \\
\hline Typical power intensity & $2.65 \mathrm{~V}$ \\
\hline Intensity of short circuit & $2.9 \mathrm{~V}$ \\
\hline Voltage of open circuit & $21.4 \mathrm{~V}$ \\
\hline
\end{tabular}

The switching frequency is selected at $100 \mathrm{kHz}$ and the current ripple will be limited at $30 \%$ of maximum load.

We have now our input-output parameters values which are:

$$
\begin{aligned}
& V_{\text {in }}=17 \mathrm{~V}, V_{\text {out }}=12 v, I_{\text {Load }}=2 \mathrm{~A} \\
& f_{\text {sw }}=100 \mathrm{kHz}, \alpha=\frac{V_{\text {out }}}{V_{\text {in }}}=0.705, \\
& I_{\text {ripple }}=0.3 . I_{\text {Load }} .
\end{aligned}
$$

From Figure 4 we can obtain directly the value of the inductor $L$ :

$$
L=\left(V_{\text {in }}-V_{\text {out }}\right) \cdot\left(\alpha / f_{\text {sw }}\right) / I_{\text {ripple }}
$$

Calculate: $\quad L=58.75 \mu H$.

\subsection{Output capacitor selection:}

An insufficient output capacitance and a high equivalentseries resistance (ESR) in the output capacitor caused a large overshoots and a large voltage ripple in the output. So we must include an output capacitor with ample capacitance and low ESR in order to resolve this problem.

From (17) we have: $\quad C=\frac{1}{8 L f^{2} \Delta V_{o u}} V_{o u}$

Define ripple voltage $\quad \Delta V_{o u}=50 \mathrm{mv}$,

Calculate: $\quad C_{\text {out }}=128 \mu \mathrm{F}$. (minimum)

NB: The capacitor ESR value was selected from a vendor's catalog. Given the ripple current and the target output voltage ripple, an ESR value of $0.030 \mathrm{ohm}$ was selected from a list of capacitors rated for 0.6 amp ripple current.

\subsection{Input capacitor selection:}

Like the output capacitor, the input capacitor selection is primarily dictated by the ESR requirement needed to meet voltage ripple requirement. Usually, the input voltage ripple requirement is not as stringent as the output voltage ripple requirement. In our application the PV module generates the most watts running at around $17 \mathrm{v}$, so after consulting catalogue a capacitor $C_{\text {in }}=330 \mu \mathrm{F}(35 \mathrm{v})$ was selected with ESR value of $0.12 \mathrm{ohm}$ for more efficiency.

\subsection{Diode selection:}

Power dissipation is the limiting factor when choosing a diode. This power can be calculated by the following equation:

$$
P_{\text {diode }}=(1-\alpha) \cdot I_{\text {load }} \cdot V_{D}
$$

Where $V_{D}$ is the voltage drop across the diode at the given output current $I_{\text {out }, \max } \quad$ (Typical values are $0.7 \mathrm{v}$ for a silicon diode and $0.3 \mathrm{v}$ for a Schottky diode). By using a schottky diode, switching losses are negligible. Ensure that the selected diode will be able to dissipate that much power.

The maximum reverse voltage on the diode in this application is 17 volts.

A $M B R 735,35 \mathrm{v}, 7.5 \mathrm{~A}$ Schottky meets requirements was selected.

\subsection{MOSFET selection:}

Assume:

$V_{\text {in }}=17 v, I_{\text {Load }}=2 A, \alpha=0.705, f_{\text {sw }}=100 \mathrm{khz} . \quad$ an MOSFET IRFZ44 N-fets were chosen for their low Rdson $(0.02 \Omega)$ in order to minimizes both the power dissipation and the temperature rise.

\section{VERIFYING PERFORMANCE}

Our Buck converter (Figure 6) was simulated to check performance by using the equations in this article to calculate values for the critical components and characteristics required.

NB: Replacing the diode D (in Figure 1) with a MOSFET synchronous rectifier further increases the efficiency of our buck converter. [3]

The Buck converter is controlled by the PIC16F876 microcontroller [5]. The microcontroller is clocked at $8 \mathrm{MHz}$ by the crystal. The PWM output of the PIC on pin 13 is used to control the duty cycle which sets its voltage conversion ratio. The frequency of the PWM is set to $100 \mathrm{KHz}$ by the PIC software. The PWM duty cycle is controlled by the PIC software to stabilize the output voltage at around $13.5 \mathrm{v}$ to keep the battery at its fully charged value. 


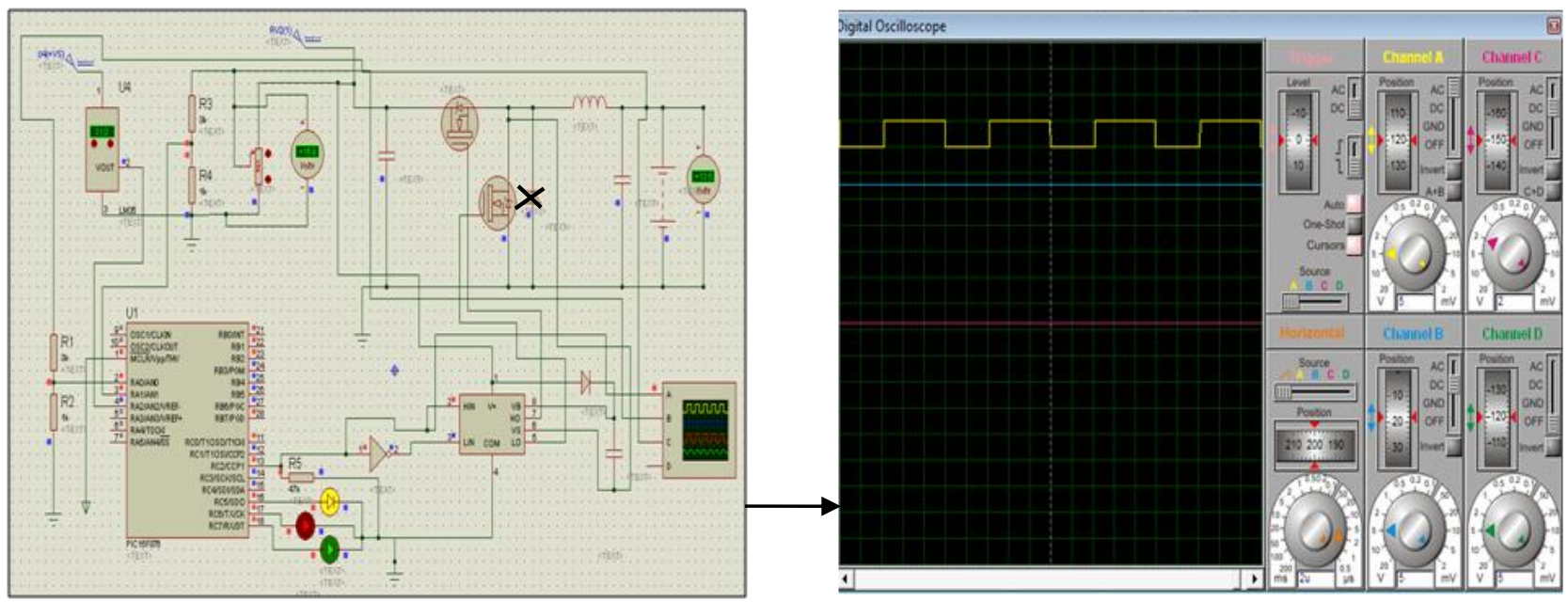

Fig. 6 Buck converter with a MOSFET synchronous

The efficiency of our regulator was tested by a test-bench including a computer, a data-acquisition: KEITHLEY 2700/7700, one solar panel PWX500, two lead-acid batteries: GLS6/270Ah-6v, and one lamp 12v/50w [4, 5]. (Figure7)

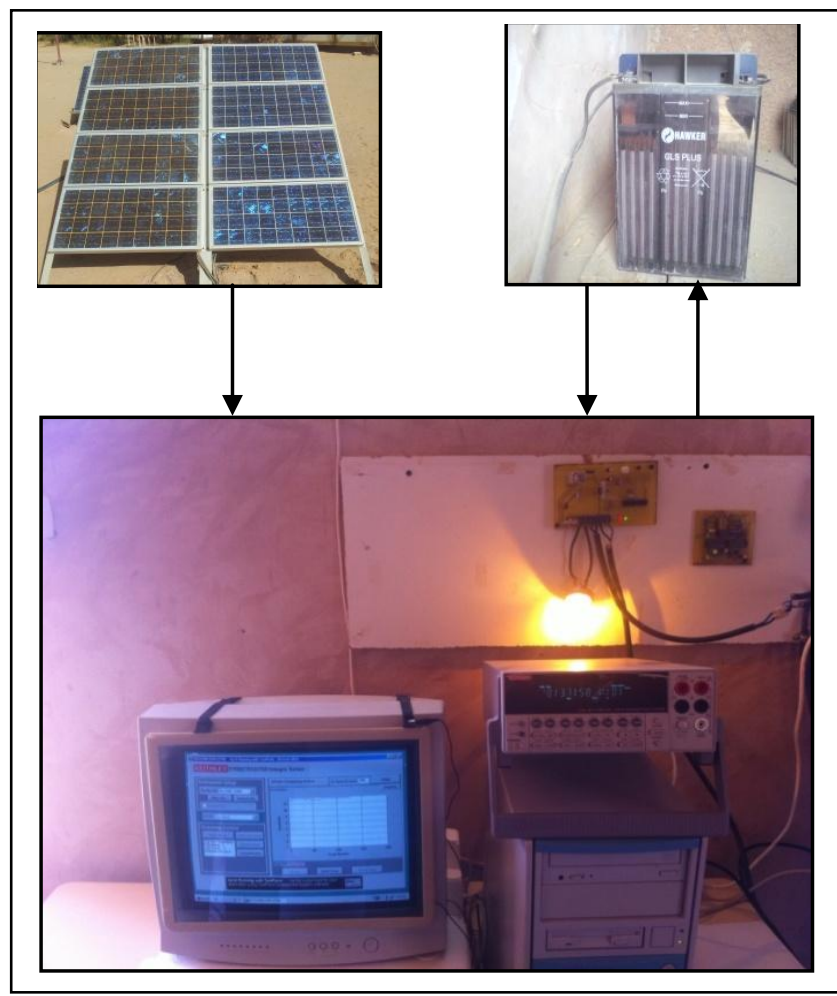

The PIC reads the input and the output voltage of the Buck converter through the A/D converter on pins 2 and 3 . $(\mathrm{R} 1, \mathrm{R} 2)$ and $(\mathrm{R} 3, \mathrm{R} 4)$ make a voltage divider used to drop the input and output voltage into the $5 \mathrm{v}$ range that can be read by the PIC. The PIC uses the LEDs as indicators to show the software state.

And for more efficiency, an LM35 (Precision Centigrade Temperature Sensors) was used to take care of temperature variations. [12] rectifier Since our load is a battery (where the terminal voltage was fixed by the battery), we have tested our Buck converter where we note that our Buck shows a good stability compared to the variation of the meteorological conditions, and controls well the battery voltage during the charging period. The following figure (Figure8) shows the battery tension evolution according to time.

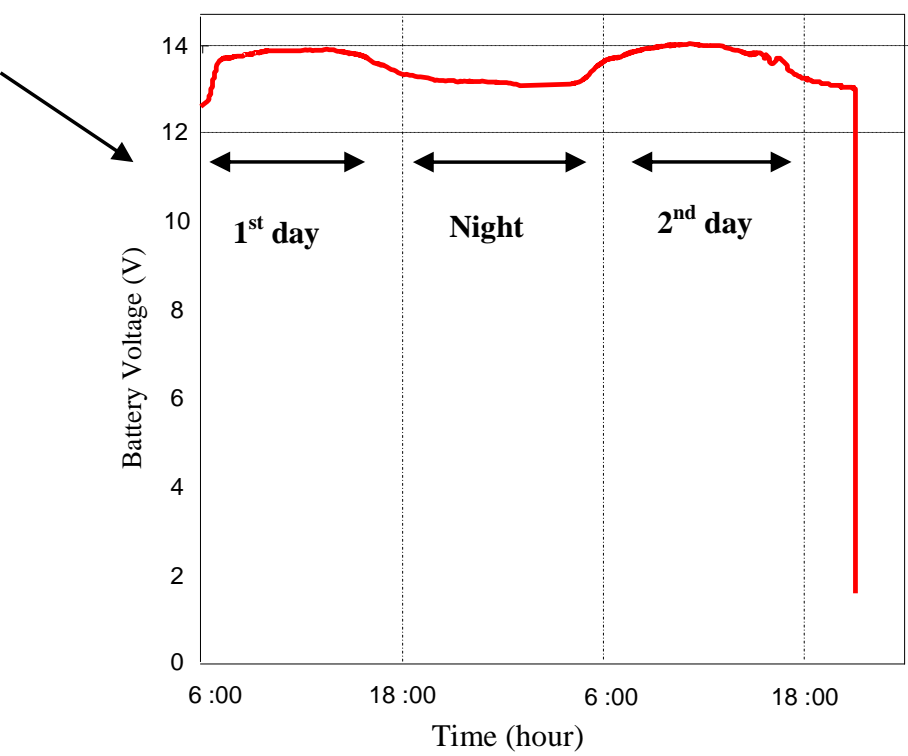

Fig. 8 Battery voltage evolution.

The voltage of the battery rises during the charging period, reaching a maximum value when charge is completed, this value depends on temperature, and voltage reading must be corrected by: $[6,7]$

- $-0.005 \mathrm{v}$ per degree above $25^{\circ} \mathrm{C}$.

- $+0.005 \mathrm{v}$ per degree below $25^{\circ} \mathrm{C}$ 


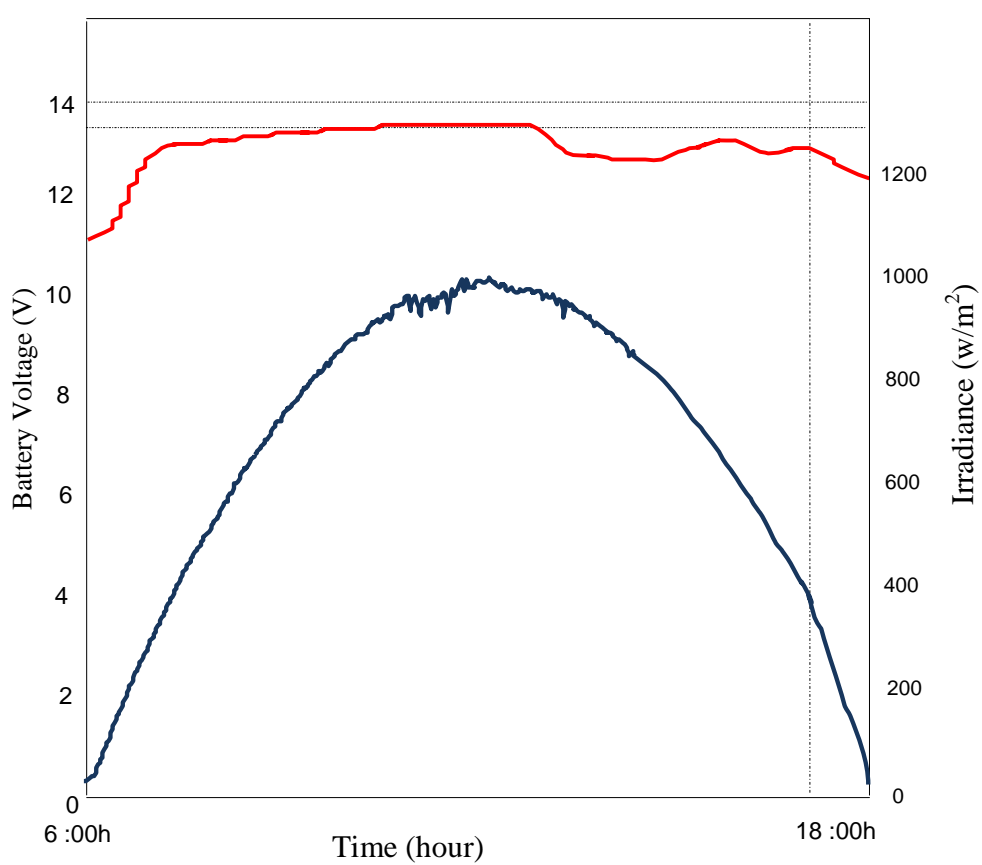

Fig. 9 Irradiance effect (experimental data).

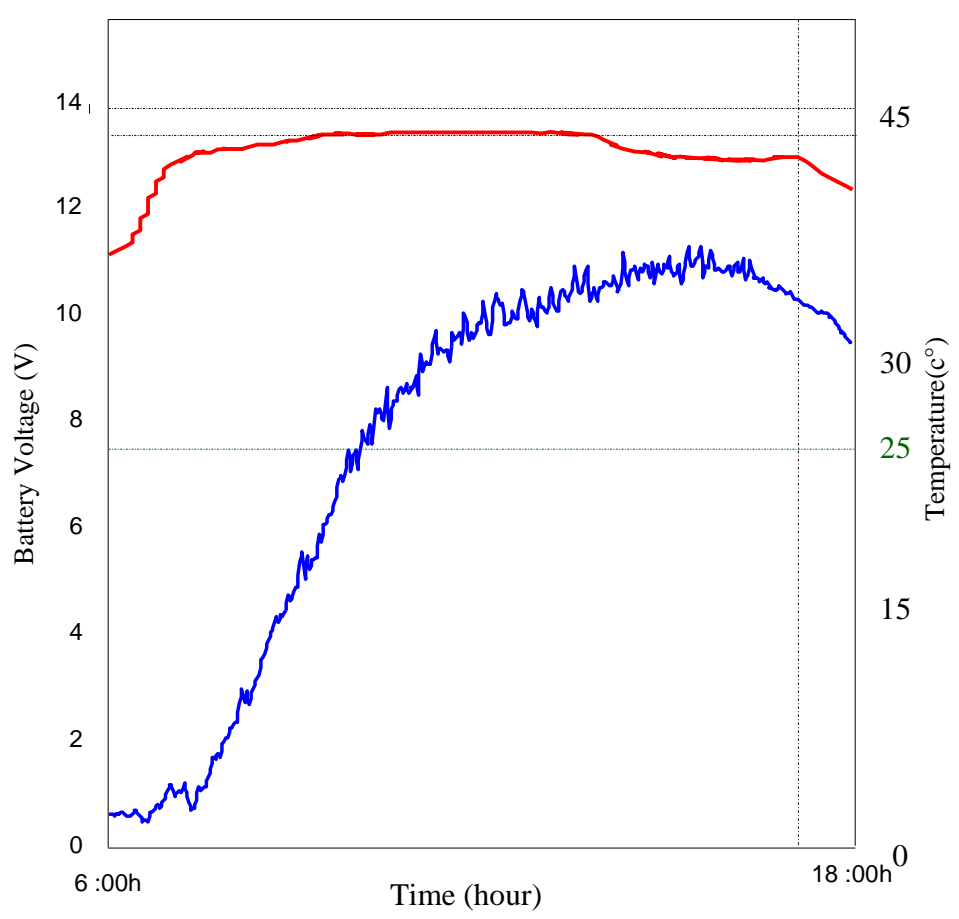

Fig. 10: Temperature effect (experimental data).

\section{CONCLUSION}

Minimizing power loss throughout the converter will extend battery life and reduce heat dissipation and from catalogs and data sheets we can obtain and calculate power loss in each section of the converter.
In this application, the output Power is:

$\begin{array}{ll}24 \text { watts }(12 \mathrm{~V} * 2 \mathrm{~A}) ; & \\ \text { Input capacitor loss: } & 0.12 \mathrm{~W} \\ \text { MOSFET Loss: } & 0.30 \mathrm{~W} \\ \text { Diode Loss: } & 0.47 \mathrm{~W} \\ \text { Inductor Loss: } & 0.15 \mathrm{~W} \\ \text { Output Capacitor Loss: } & 0.01 \mathrm{~W} \\ \text { Total losses: } & 1.05 \mathrm{~W}\end{array}$

Efficiency $=(24 \mathrm{~W}-1.05 \mathrm{~W}) / 24 \mathrm{~W}=95 \%$.

The lab-test of this circuit verified final electrical and thermal specifications and proved that the synchronous rectification can increase a power converter's efficiency significantly and for minimal cost.

\section{REFERENCES}

[1] R. Sudharshan Kaarthik"; Modelling, Simulation and Implementation of Low Power Photovoltaic Energy Conversion System", National Institute of Technology Rourkela, Rourkela - 769008, India; 2010.

[2] D.W. Hart "Introduction to Power Electronics", Prentice Hall, 1997.

[3] B.K. Bose "Modern Power Electronics and AC Drives", Prentice Hall, 2002.

[4] Bigonff La programmation des PICs, Secode partiePIC16F876/877, Rev 7.

[5] Microchip PIC 16F87X Data Sheet (DS30292C).

[6] Putting into service of dry charged batteries; OLDHAM France S.A.

[7] Qun Zhao and Fred C. Lee : "High-Efficiency, High Step-Up DC-DC Converters", IEEE Transactions on Power Electronics, Vol.18, No.1 pp.65-73 (2003)

[8] E. Arango, J. Calvente, R. Giral, Asymmetric Interleaved DC-DC Switching Converters: Generation, Modelling and Control, 1st ed., Lambert Academic Publishing, Saarbrucken, 2010.

[9] A. Menti, T. Zacharias, J. Milias-Argitis, Harmonic distortion assessment for asingle-phase grid-connected photovoltaic system, Renew. Energy 36 (2011) 360368 .

[10] C.A. Ramos-Paja, E. Arango, DC/DC pre-regulator for input current ripple reduction and efficiency improvement, Electric Power Systems Research 81 (2011) 2048- 2055

[11] P. Thounthong, B. Davat, Study of a multiphase interleaved step-up converter for fuel cell high power applications, Energy Convers. Manage. 51 (2010) 826832.

[12] LM35Precision Centigrade Temperature Sensors National semiconductor data sheet. 